\title{
Chapter 3 \\ Core Principles and Concepts in Land-Use Modelling: A Literature Review
}

\author{
Jonas van Schrojenstein Lantman, Peter H. Verburg, \\ Arnold Bregt, and Stan Geertman
}

\subsection{Introduction}

Simulation models of land use predict or describe land-use change over space and time. Recent overviews of land-use simulation models show an overwhelming amount of different types of models and applications (Heistermann, Muller \& Ronneberger, 2006; Koomen, Stillwell, Bakema \& Scholten, 2007; Verburg, Schot, Dijst \& Veldkamp, 2004). Obviously, such models are simplifications of reality, but increasing computing power over the years has made it possible to incorporate more and more complexity in such models. This increased complexity, however, tends to obscure the theoretical foundations of land-use simulation models. This theoretical foundation relates to the core principles that are used to explain land-use change and the concepts that are applied to translate these principles into a functioning model of land-use change. An in-depth review of land-use change concepts, their underlying principles, applicability and translation into actual models does not exist to our knowledge. In this chapter we aim, therefore, to analyse the application of various theoretical concepts of land-use change that are used in modelling. This analysis is a first step to better understand the conceptual background of land-use change and the application of these concepts in computer simulation models. Based on this review we present some observations on important research issues in land-use modelling and suggest possible ways for further model improvement.

Computer simulation models of land use are characterised in terms of core principles and applied concepts in Section 3.2. After this discussion of the theoretical background of current land-use models we dwell on two additional issues that are important for improving simulation models of land-use change. Lessons from model validation efforts are described in Section 3.3, while the importance of scale issues in land-use change is dealt with in Section 3.4. The main conclusion and discussion can be found in Section 3.5, whereas some themes for future research are suggested in Section 3.6. The latter suggestions are specifically focused on the Dutch LUMOS models.

J. van Schrojenstein Lantman $(\bowtie)$

Nelen \& Schuurmans, PO Box 1219, 3500 BE Utrecht, The Netherlands

e-mail: jonas.vanschrojenstein@nelen-schuurmans.nl 


\subsection{Categorising Land-Use Simulation Models}

In the literature, various categorisations of computer simulation models of land-use change have been made. Baker (1989) categorised them according to scale: whole landscape models, distributional landscape models and spatial landscape models. Briassoulis (2000) categorised models according to the modelling tradition to which they belong: statistical/econometric, spatial interaction, optimisation, integrated and 'other' modelling approaches. Lambin, Rounsevell, and Geist (2000) distinguished between empirical-statistical, stochastic, optimisation, dynamic simulation, and integrated modelling approaches. Agarwal, Green, Grove, Evans, and Schweik (2001) analysed 19 different computer simulation models according to a three-dimensional framework: space, time, and human decisionmaking. Verburg et al. (2004) discussed computer simulation models according to six features: level of analysis, cross-scale dynamics, driving factors, spatial interaction and neighbourhood effects, temporal dynamics, and level of integration. Heistermann et al. (2006) classified 18 computer simulation models according to geographical, economic and the integration of both. Koomen and Stillwell (2007) did not categorise models at all, but rather discussed a number of characteristics of computer simulation models: static/dynamic, transformation/allocation, deterministic/probabilistic, sectoral/integral, zones/grid.

Common factors in these categories of computer simulation models can be recognised (for example, distinction between dynamic and integrated models), but differences in approach make these studies difficult to compare. The general complexity of computer simulation models and the fact that the field of land-use modelling is interdisciplinary are the most probable reasons for the different categorisations made by these authors. Yet, despite the marked differences between computer simulation models of land-use change, they do have a common basis.

It is common practise for modellers to describe the processes of land-use change according to a particular concept or mechanism that can be used to characterise land-use changes (e.g. Cellular Automata). In fact, a concept of land-use change is composed of a set of core principles according to which 'real world' processes of land-use change are assumed to operate (e.g. Cellular Automata is based on neighbourhood interaction). This concept of land-use change is then codified into algorithms, for which other, different algorithms can be used, which will in turn lead to different computer simulation models (e.g. Environment Explorer or GEOMOD2). Thus, a land-use change algorithm is no more than the translation of a concept of land-use change into calculation rules for a computer simulation model.

Figure 3.1 shows the relationship between the process of land-use change and computer simulation models. The grey box encloses the steps that are the focus of this chapter. Although different divisions can be made, all computer simulation models have in common that they are based on four core principles. The main steps in Fig. 3.1 are discussed in the following subsections. 


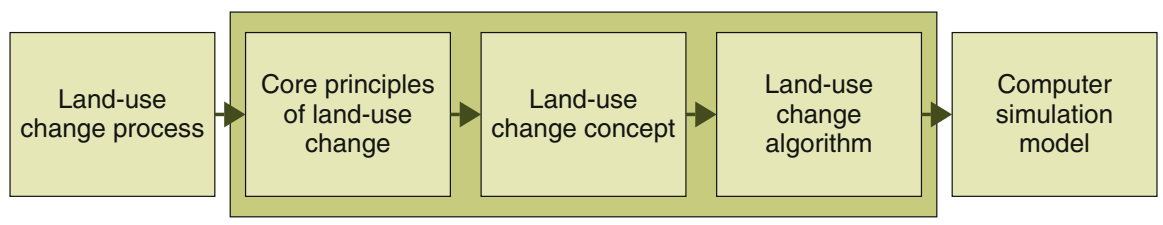

Fig. 3.1 Relationship between the land-use change process and computer simulation models

\subsubsection{Land-Use Change Process}

'Land use change is the result of socio-economic and biophysical phenomena, dependent on spatial location, scale, and existing land use' (Briassoulis, 2000; Lambin et al., 2001; Lesschen, Verburg \& Staal, 2005; Meyer \& Turner, 1992; Turner et al., 1995). In our literature review we focused on concepts of land-use change and their origin, not on the process of land-use change itself. Nevertheless, the literature mentioned in this subsection provides a good starting point for reading on land-use change processes.

\subsubsection{Core Principles of Land-Use Change}

In-depth analysis of the literature on land-use modelling shows that all simulation models of land use are based on at least one of the following four core principles of land-use change:

1. Continuation of historical development;

2. Suitability of land (in monetary or other units);

3. Result of neighbourhood interaction; or

4. Result of actor interaction.

\section{Continuation of Historical Development}

The premise behind historical land-use change is that future land use can be predicted by means of historical changes. This can be interpreted in several ways: in the past people liked to live near the water, so in the future they will like to do so too; or $15 \%$ of the forest became residential land so it is likely that given the same time horizon this will happen again.

Extrapolating land-use change from past changes into future changes is an intuitive concept and is, therefore, widely used. A business-as-usual scenario is a practical application of this principle, as demonstrated by Kuijpers-Linde et al. (2007).

\section{Suitability of Land (in Monetary or Other Units)}

Suitability may cover a combination of factors, such as soil suitability, spatial location or terrain characteristics of a piece of land; distance to a market is an aspect 
of spatial location. The underlying premise is that people want to maximize profit, which can be expressed either in monetary units (quantitative) or non-measurable units (qualitative).

\section{Result of Neighbourhood Interaction}

The principle of neighbourhood interaction states that the possibility of transition from one use of land to another is dependent on the land use of its surrounding cells. This driver can be biophysical, e.g. a land cover affecting that of neighbouring cells, or a socio-economic one; the latter can be explained with, for example, the Core and Periphery model, which assumes that people want to maximise profit (Fujita, Krugman \& Venables, 1999; Krugman, 1991; 1999).

\section{Result of Actor Interaction}

The main assumption in actor-focused decision-making is that land-use change is the result of interaction between actors. Actors can be represented as agents: a single entity or a group of actors, depending on the scale of modelling. The core principle of actor decision-making aims at explaining and understanding socio-economic drivers and policies for development. A complicating factor is that it is only recently that surveys have been held among actors in certain case studies in which their preferences were monitored. Therefore, the amount of data is insufficient and it is difficult to validate them. In practice this core principle of land-use change modelling is still in its infancy, but it seems to be a promising research tool (Matthews, Gilbert, Roach, Polhill \& Gotts, 2007).

\subsubsection{Land-Use Change Concepts}

Different concepts of land-use change represent differing attempts to enable science to explain and thus translate reality on the ground into a model; each concept brings with it its own advantages and disadvantages. Any concept of land-use change is always based on one or more of the four core principles described in the previous subsection.

\section{Quantity of Subjects in the Literature on Land-Use Change Modelling}

The following well-known concepts of land-use change were selected from the literature:

- logit functions;

- markov chains;

- cellular automata (CA); and

- agent-based modelling.

A search of the Scopus database was made for each concept. With access to over 15,000 peer-reviewed journals (Scopus, 2008), Scopus is the largest abstract and citation database of research literature and quality web sources. In addition to basic 
information such as author(s), year of publication and name of journal, the citation count for each concept was compiled. As references in Scopus only go back as far as 1996, articles published before then were not taken into account.

Subject experts selected the following search terms:

- 'artificial neural networks' AND 'land use';

- 'cellular automata' AND 'land use';

- 'agent-based' AND 'land use';

- 'agent based' AND 'land use';

- 'Markov' AND 'land use'; and

- 'logit' AND 'land use'.

The search was performed in February 2008 and the papers found were classified according to the concept in use. Papers in which two different concepts are compared were counted as an occurrence of both concepts. A paper describing a model combining two (or more) concepts was counted as hybrid paper. Some papers described concepts only in theory, while other papers described concepts as applied in case studies. After the analysis, the database was checked for any key papers that were missing; these were added when necessary. Figure 3.2 shows the results of the literature search. It was remarkable that, with hybrid and CA papers combined, CA appeared in over $40 \%$ of the papers published on land-use modelling. Apart from the obvious fact that CA is a popular concept among scientists modelling land use, other explanations are possible. One of them is that when an article is written on the use of cellular automata, it receives this keyword

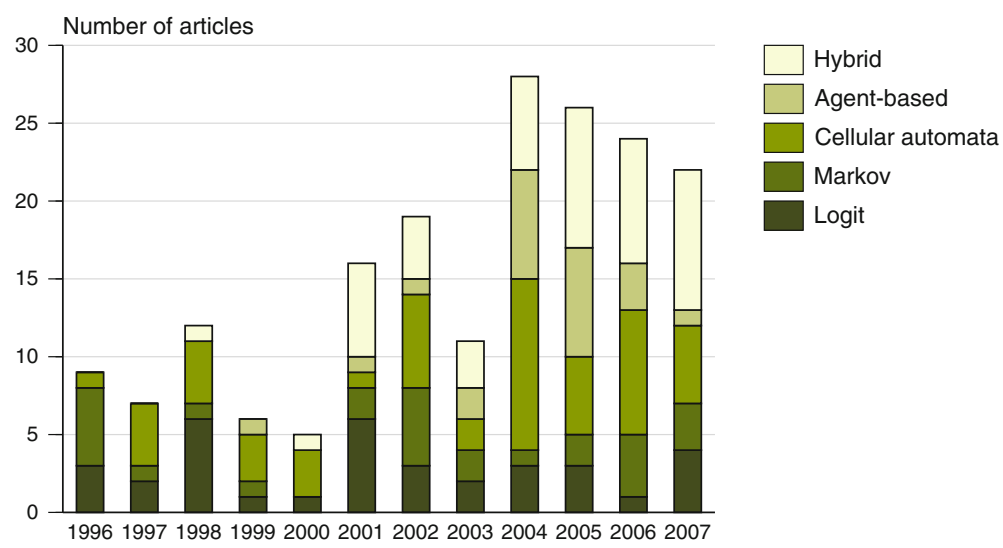

Fig. 3.2 Scientific articles in Scopus ${ }^{1}$ on various concepts of land-use change

\footnotetext{
${ }^{1}$ Scopus is the largest abstract and citation database of research literature and quality web sources. It is designed to find information scientists need. Quick, easy and comprehensive, Scopus provides superior support for literature searches. Surf to www.scopus.com.
} 
from the author. If, however, an article is written about a land-use model based on a logit concept, the keyword selected by the author may not be 'logit'. Our Scopus literature search is, therefore, merely an indication of the number of articles written about certain concepts of land-use change.

\subsubsection{Concepts of Land-Use Change in Practice}

The following concepts of land-use change were identified in the literature:

- cellular automata;

- statistical analysis;

- Markov chains;

- artificial neural networks;

- economics-based models; and

- agent-based systems.

In this subsection, each concept will be discussed in terms of the basic principle of the concept and its use in practice.

\section{Cellular Automata (CA)}

The most well-known land-use change concept is that of cellular automata (Langdon, 1998; White and Engelen, 1994). The basic principle of CA is that landuse change can be explained by the current state of a cell and changes in those of its neighbours. It is, thus, based on the core principles of continuation of historical development and result of neighbourhood interaction. In other words: if a road through a forest is paved, this enhanced the connectivity of the region, with the result that forest land use is replaced by residential use. CA comprises four elements: cell space; cell states; time steps and transition rules (White \& Engelen, 2000). Decision rules can be expert-based or derived from statistical analysis. Two main types of CA can be distinguished: unconstrained and constrained. Unconstrained is the most 'true' CA, as it only uses decision rules to calculate land-use change. In constrained $\mathrm{CA}$, the amount of land-use change per land use class is limited; the limit of a certain land-use class is either expert-based or calculated from historical land use.

Made famous by Gardner (1970), John Conway's game of life is the best known example of a cellular automaton to date. Tobler (1979) was the first to introduce the use of cellular automata in geography. In the decades that followed this was further developed by Couclelis (1985), Batty and Xie (1994), and White and Engelen (2000). More recently, Hagoort (2006) has put together a nice overview of the history of CA, and Pinto and Antunes (2007) provide an overview of the use of CA in urban studies. In the Netherlands, a constrained CA model (Engelen, White, Uljee \& Drazan, 1995; Geertman, Hagoort \& Ottens, 2007) called the Environment Explorer (part of the LUMOS toolbox), is commonly used in spatial planning and policy-making in (de Nijs, de Niet \& Crommentuijn, 2004). 


\section{Statistical Analysis}

All kinds of statistical information can be derived from land-use maps. Statistical information can be based on all four core principles, depending on the aim of the research. A widely used application is the computer program FRAGSTATS by McGarigal and Marks (1995), which can analyse ample amounts of landscape statistics. In the discipline of land-use modelling, linear regression, probit regression, binomial logit and multinomial logit models are used to analyse statistical relations in land use and predict future patterns. Logit analysis provides an interpretable linear model (deMaris, 1992). Logistic regression is used to analyse the probability of occurrence, dependent on different factors, of a certain landuse category, for instance biophysical characteristics, distance from location to the market (Verburg, Ritsema, van Eck, de Nijs \& Schot, 2004). The coefficients for the conversions can be calculated from historical land use and extrapolated to the future. A logit model can be based on neighbourhood interaction, historical landuse change, soil suitability, spatial location or combinations of these. A binary logit model is a mathematical variant of an ordinary linear model that will give a prediction of land-use change relative to all other options. A multinomial logit (MNL) model is similar, with the exception that it describes the conversion of different land-use categories relative to a reference category (deMaris, 1992; Liao, 1994; Wrigley, 1976).

Among the first to apply logit models in relation to land-use change were Veldkamp and Fresco (1996), with the CLUE model, and Wear and Bolstad (1998), who linked a negative binomial regression model of building density with a logit model of land use. An example of MNL analysis is given in Walsh, Soranno, and Rutledge (2003), where spatial association of various categories of land use is analysed. Land Use Scanner (Hilferink \& Rietveld, 1999), which has been used in producing sustainability outlooks for the Netherlands (Borsboom-van Beurden et al., 2005; Kuijpers-Linde et al., 2007), is an example of the use of logit modelling in the planning and policy environment.

\section{Markov Chains}

Burnham (1973) was one of the first to propose using Markov chain analyses for modelling land-use change. Such analyses are based on the core principle of a continuation of historical development. A Markovian analysis uses matrices (e.g. Table 3.1) to represent changes between land-use categories.

Table 3.1 Example of a Markov matrix

\begin{tabular}{llll}
\hline Current $\backslash$ future land use & Farmland & Peri-Urban & Urban \\
\hline Farmland & 0.50 & 0.40 & 0.10 \\
Peri-urban & 0 & 0.8 & 0.2 \\
Urban & 0 & 0.1 & 0.9 \\
\hline
\end{tabular}


Under an assumption of stationarity (temporal rate of change and amount of change stay the same), the matrix can be used to calculate the probability of landuse change of one land-use category to another. A disadvantage of this type of analysis is that it is non-spatial, meaning that additional assumptions are required for allocation. Distinction is made between a first-order and second-order Markov matrix. The former uses a matrix with current land use and a change matrix based on expert knowledge, while the latter calculates changes from one land use to another by comparing two maps of land use over time, that is, this change matrix is constructed from historical land-use change. The temporal rate of change is assumed to be constant, so the change matrix can then be used in the same way as in first-order Markov analysis.

Examples of Markov chains in land-use studies are given by Muller and Middleton (1994), Fearnside (1996) and Lopez, Bocco, Mendoza, and Duhau (2001). Because of its simplicity, Markovian analysis is a popular technique to combine with other concepts. The GEOMOD2 model (Pontius, Cornell \& Hall, 2001) is an example of combining Markov techniques with statistical analysis.

\section{Artificial Neural Networks}

The use of artificial neural networks (ANNs) in land-use modelling has increased substantially over the last few years because of advances in computing performance and the increased availability of powerful and flexible software (Skapura, 1996). ANNs are self-learning computer models and are used for pattern recognition in many disciplines (Pijanowski, Brown, Shellito \& Manik, 2002). Recently, ANNs have found their way into the world of land-use modelling. The ANN algorithm assumes a relation between past and future land-use change and can be linked to suitability maps. ANNs can be based on all four core principles. The first to apply ANNs to a computer simulation model was Pijanowski et al. (2002). The model 'trains' itself on a dataset and the corresponding land-use maps of different years enabling it to recognise and reproduce the pattern of land-use categories (Mas, Puig, Palacio \& Sosa-Lopez, 2004; Pijanowski, Pithadia, Shellito \& Alexandridis, 2005).

\section{Economics-Based Models}

Although not exactly a concept of land-use change, but rather more a land-use theory, economics-based models of land use cannot be left out of the list of concepts of land-use change. These models are based on the core principle of suitability of land (in monetary or other units), although the core principle of continuation of historical development can also be included. The first theory on land use was developed by Johan Heinrich von Thünen in 1826. It was translated into English in 1966 (von Thünen, 1966). Von Thünen converted the principle of Ricardo (1817) that profit will be used to reinvest in a land-use change concept. Von Thünen stated that as long as the profit of a commodity (turnover minus production costs) is higher than the transportation costs of the commodity, the land will continue to be used to produce this commodity. Alonso (1964) expanded this theory by including land-use suitability and an individual bid-price curve for every household or firm. A little later Sinclair (1967) expanded von Thünen's theory to explain urban sprawl. More recent 
applications of the theory have been reported by Chomitz and Gray (1996), Nelson and Hellerstein (1997), and Walker (2004) which all use von Thünen's model as the base theory to explain tropical deforestation.

\section{Agent-Based Systems}

Be it agent-based modelling, individual-based modelling, micro-simulation or activity-based modelling, the common ground of all these concepts of land-use change is that they are based on the core principle of actor interaction. The differences between these approaches are to be found in the institutional dimension of scale, for example, ranging from individual modelling to group behaviour and the number of agents being modelled. One of the first actor-interaction based models was a competition model for individual trees (Bella, 1971), but it took a long time before this type of model was applied to land-use change. Balmann (1996) was one of the first to introduce a spatially dynamic model of land-use change for analysing structural change in agriculture in which individual farmer preferences were taken into account. Since 1996 the number of articles on agent-based land-use models has steadily grown over the years (Fig. 3.2). Within agent-based systems, we distinguish four sub-types: agent-based modelling; individual-based modelling and micro-simulation; activity-based modelling; and expert-based decision rules.

An agent-based model of land-use change consists of two key components: a map of the study area, and a model with agents that represent human decisionmaking (Parker, Berger \& Manson, 2001). The preferences of agents can be defined by expert judgement, by using questionnaires, or by using an artificial neural networks technique. A multi-agent system is a set of agents interacting in a common environment, which consists of everything in the model that is not an agent (Ferrand, 1996; Le Page, Bousquet, Bakam, Bah \& Baron, 2000). An agent is a representation of an actor in the process of land-use change and can be either an individual or a group. The following actor interactions can be distinguished (Ligtenberg, Bregt \& Lammeren, 2001):

- interactions between the spatial objects of the environment and actors;

- interactions between spatial objects;

- interactions between actors and spatial objects; and

- interactions between actors and other actors.

Originating in the discipline of ecology, individual-based modelling is a subset of agent-based modelling. It differs from the agent-based modelling usually done in that the scale of the concept is always at the individual level. Each individual is represented as an agent, each with their own preferences (Grimm et al., 2006). In social sciences, micro-simulation models aim at reproducing human behaviour at the individual level (Moeckel, Schurmann \& Wegener, 2002). Micro-simulation is mostly used to model urban land use and transport that is under development; an example of this approach is the Ilumass project (Wagner \& Wegener, 2007).

Activity-based modelling is a special subset of the agent-interaction decisionmaking concept. A relatively new concept in research on land-use modelling, 
activity-based modelling is based on the work of Arentze and Timmermans (2000) and the UrbanSim model (Waddell, 2002). In the Netherlands, there is need for policy-makers to know the impact of intensification of cities as compared to that of urban sprawl. In activity-based modelling, the relation between mobility and infrastructure and their impact on land-use change is explicitly addressed which in turn can be used to recognise, for example, traffic bottlenecks. The concept of activity-based modelling is relatively new and opinions on what an activitybased model exactly is differ. It can range from modelling of population density in combination with CA, to a sort of individual-based model in which, for example, the result of movements per individual during the day is taken into account, which can help recognise possible traffic jams.

In cases of uncertainty about parameters, expert-based rules, which encapsulate experts' knowledge of a specific area, are used to estimate them. Basically, all four core principles can be used for this. The IMAGE model (Alcamo, Kreileman, Krol \& Zuidema, 1994a; 1994b) is an example of a land-use model built on expert-based decision rules.

Analysis of concepts of land-use modelling in practice and the models involved allows modellers to pick the most appropriate concept of land-use change for the study area under investigation. The relation between land-use change concepts and underlying core principles is shown in Table 3.2.

\subsubsection{Selection of Operational Land-Use Simulation Models}

This subsection contains a selection of computer simulation models of land-use change. Various models have been developed that can estimate future land use.

Table 3.2 Relation between concepts of land-use change and core principles

\begin{tabular}{|c|c|c|c|c|}
\hline $\begin{array}{l}\text { Concept of land-use } \\
\text { change }\end{array}$ & $\begin{array}{l}\text { Continuation } \\
\text { of historical } \\
\text { development }\end{array}$ & $\begin{array}{l}\text { Suitability } \\
\text { of land } \\
\text { (in monetary } \\
\text { or other units) }\end{array}$ & $\begin{array}{l}\text { Result of } \\
\text { neighbourhood } \\
\text { interaction }\end{array}$ & $\begin{array}{l}\text { Result of actor } \\
\text { interaction }\end{array}$ \\
\hline Economics-based models & $\mathrm{P}$ & $\mathrm{A}$ & - & - \\
\hline Agent-based models & $\mathrm{P}$ & $\mathrm{P}$ & $\mathrm{P}$ & A \\
\hline Cellular automata & A & $\mathrm{P}$ & A & - \\
\hline Statistical analysis & $\mathrm{P}$ & $\mathrm{P}$ & $\mathrm{P}$ & $\mathrm{P}$ \\
\hline Markov chains & A & - & - & - \\
\hline Artificial neural networks & $\mathrm{P}$ & $\mathrm{P}$ & $\mathrm{P}$ & $\mathrm{P}$ \\
\hline $\begin{array}{l}\text { Individual based } \\
\text { modelling and } \\
\text { micro-simulation }\end{array}$ & $\mathrm{P}$ & $\mathrm{P}$ & $\mathrm{P}$ & A \\
\hline Activity-based models & $\mathrm{P}$ & $\mathrm{P}$ & $\mathrm{P}$ & A \\
\hline $\begin{array}{l}\text { Expert-based decision } \\
\text { rules }\end{array}$ & $\mathrm{P}$ & $\mathrm{P}$ & $\mathrm{P}$ & $P$ \\
\hline
\end{tabular}

$\mathrm{A}=$ Always, $\mathrm{P}=$ Possible,$-=$ Not possible or not practical 
For reviews of some of these models see Agarwal et al. (2001), Hunt, Kriger, and Miller (2004), and Verburg et al. (2004). All such models use different concepts and algorithms to decide where and when land-use change will take place. It is beyond the scope of this chapter to describe all the land-use models available: only models from the LUMOS toolbox and a small selection found in the literature are described. The models are described only briefly here as computer simulation models of land-use change are not the focus of this chapter.

The LUMOS toolbox consists of Land Use Scanner and Environment Explorer (LUMOS, 2005). Land Use Scanner allocates land according to bid prices for various types of land use (Hilferink \& Rietveld, 1999; Koomen, Loonen \& Hilferink, 2008). The possibility of government intervention in determining land use is taken into account by, among other things, adding aggregate constraints. Environment Explorer is built on a local-level Cellular Automata model constrained by regional-level spatial interaction model (White \& Engelen, 2000).

Other well-known land-use models are:

- CLUE (Conversion Land Use and its Effects) is a dynamic simulation model using empirically-derived relations between land-use change and driving forces from cross-sectional analysis at multiple scales (Veldkamp \& Fresco, 1996; Verburg, de Koning, Kok, Veldkamp \& Bouma, 1999; 2004).

- Land Transformation Model (LTM), which combines GIS and ANNs to predict future land use. The ANNs are used to learn the patterns of development in a region, whereas GIS is used to develop the spatial-predictor drivers and perform spatial analysis on the result (Pijanowski et al., 2002).

- GEOMOD2 can be used to model both forwards and backwards in time. It selects locations for a particular type of land use based on: nearest neighbourhood interaction; political sub-region; and the pattern of biophysical attributes (Pontius et al., 2001).

- SLEUTH (Slope, Land use, Exclusion, Urban extent, Transportation and Hill shade), formerly called the Clarke Cellular Automaton Urban Growth Model, was developed for and tested on various cities in North America. It is based on cellular automata and is designed to be scalable and universally applicable (Silva \& Clarke, 2002).

- UrbanSim uses aggregate economic and spatial-interaction models, and pursues a disaggregated approach to predict changes over small time steps. It takes into account the demand for real estate at each location, and the actors and choice processes that influence patterns of urban development and real-estate prices (Waddell, 2002).

- IMAGE is an ecological-environmental framework that simulates the environmental consequences of human activities worldwide. The objective is to explore the long-term dynamics of global change. It has a relatively coarse resolution (of $5 \mathrm{~min} \times 5 \mathrm{~min}$ ) and the allocation of new land use is based on demand, location preferences and autonomous system change (Alcamo et al., 1994a; b). 
- CORMAS stands for Common-pool resources and multi-agent systems. It is a multi-agent framework in which interactions between groups of agents and a shared environment with natural resources can be simulated (Le Page et al., 2000).

- ILUMASS is a micro-simulation model of urban land use. Unfortunately, it never became fully operational, but it is a good experiment on micro-simulation of urban land use. It takes into account Land Use (Population, Accessibility, Firms), Transport (Travel demand, dynamic traffic assignment, demand for goods transport) and Environment (impacts, emissions) (Wagner \& Wegener, 2007).

\subsubsection{Core Principles and Concepts in Practice}

Our literature research has enabled us to compile an overview of the relationships between core principles, land-use change concepts, land-use change algorithms and land-use change models in practice; see Fig. 3.3. The figure links the core principles with the modelling concepts that are normally associated with it and, by way of example, indicates examples of existing land-use models that rely on that particular combination of principles and concepts. Since statistical analysis, artificial neural networks and agent-based systems can all include one of the core principles, they are connected to all the core principles. The same applies to the computer simulation

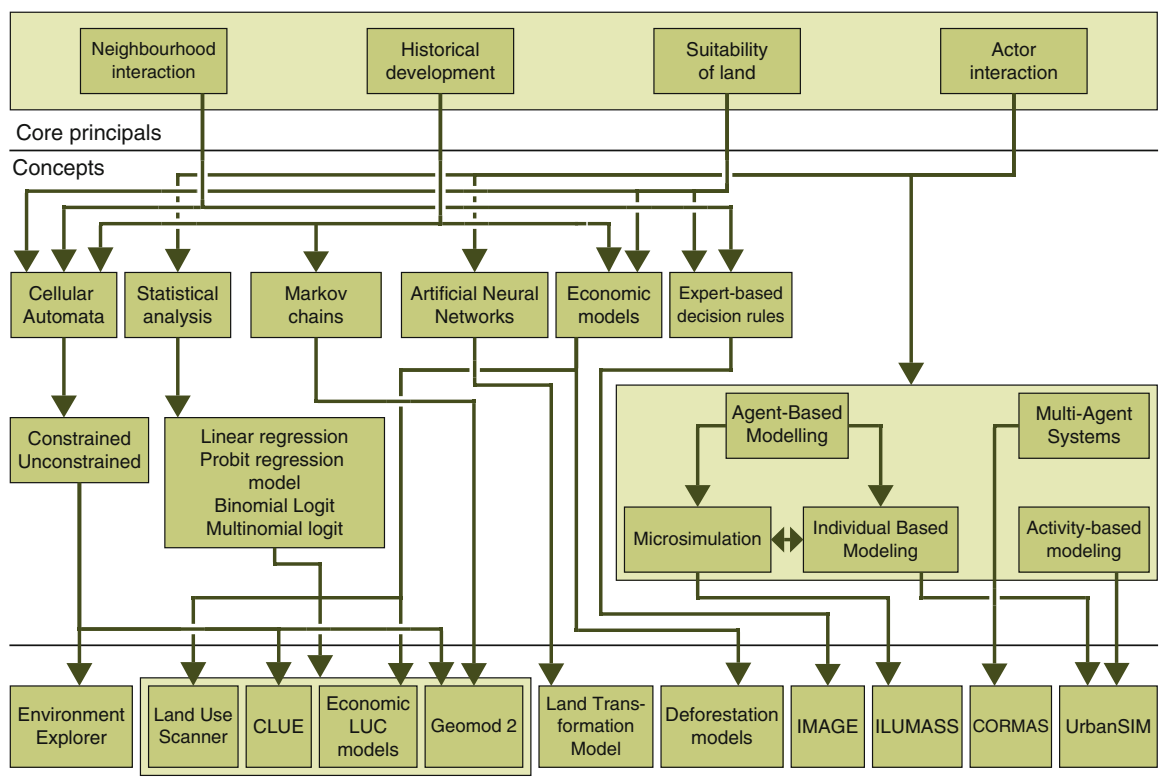

Existing computer simulation models of land-use change

Fig. 3.3 Examples of relationships between core principles, concepts and land-use simulation models in practice 
models of land-use change, for example, Land Use Scanner, CLUE, economic landuse change models and GEOMOD2, all of which incorporate statistical analysis.

This detailed overview has been compiled from the results of our literature research. Since models are mostly developed further after the initial paper is published, it is possible that some models now incorporate other or more core principles or land-use change concepts than is shown in Fig. 3.3; the same relationships between core principles and concepts of land-use change are also shown in Table 3.2.

\subsection{Lessons from Model Validation}

Validation is an essential step in assessing the performance of any land-use model (see, for example, Pontius et al., 2008). In this section we list some general lessons that can be learned from model validation and that are relevant for the further development of land-use simulation models.

Validation of land-use models consists of two elements: validation of the spatial resemblance of the output maps with reference maps; and validation of the resemblance of the described land-use change process. If a model is able to predict spatial resemblance accurately but fails to predict the process, it is questionable whether policy-makers can learn much from the results. If, on the other hand, the model is more process oriented but fails to predict spatial resemblance, it is also of little use.

In general it can be said that an inductive (data-driven) approach is strong in reproducing land-use patterns which is (spatial resemblance), but is weak in explaining correlations found. A deductive (theory-driven) approach, on the other hand, is strong in explaining how and why land use will change (which is process resemblance), but is weak in spatial allocation of land-use change (Overmars, de Groot \& Huigen, 2007).

Overmars et al. (2007) have shown that prediction of spatial location with deductive models is promising when compared to inductive models. For land-use change developments that follow a single dominant process it is expected that a deductive model will score only marginally less on spatial resemblance than an inductive model (see Fig. 3.4). For land-use changes that result from multiple processes, the differences in spatial and process resemblance between inductive and deductive simulation models increases.

One could argue that inductive simulation models, in which a lot of correlations are found, are more suitable for allocating land use at the correct spatial location. The obtained correlations, however, do not provide a causal relation and that explains why land-use change occurred at specific locations. At the other end of the spectrum are deductive models, which are aimed at modelling the process behind land-use change. Although these theory-driven models approximate the governing processes more closely than inductive models, they have more difficulty in identifying the exact spatial location of change. But since these kinds of models 
Multiple dominant land-use change processes

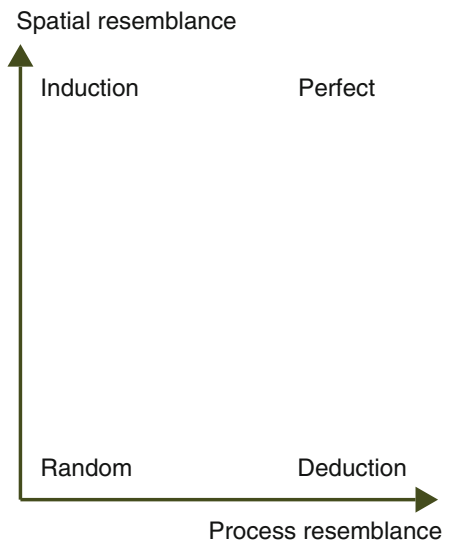

Single dominant land-use change processes

Spatial resemblance

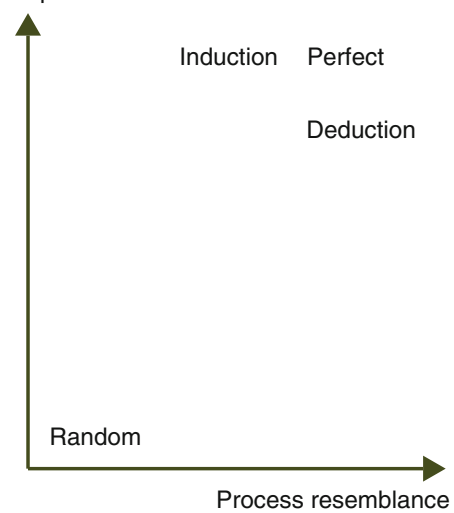

Fig. 3.4 Process resemblance versus spatial resemblance for various types of models in relation to the complexity of underlying land-use change processes

provide more insight into causality, they enhance the learning process more than inductive models.

In general, strong process resemblance is of more use to policy-makers than spatial resemblance because they can learn from the process and the interactions that take place. Ideally, however, a simulation model should be able to meet spatial and process resemblance criteria. To validate a model on its process accuracy is a difficult task since the process of land-use change is often very complex, so it is impossible to check whether the model accurately has reproduced the process. A possible technique for checking whether all key processes have been included in a model is to add other processes to the model. If the outcome, such as the landuse pattern, does not change significantly it indicates that all key processes were initially included in the model (or, at least, that the new process that was added to the model is not important in producing spatial patterns. Thus, the key processes can be identified by a combination of common sense and trial and error. To check the stability of the model, the same process can be modelled several times. If the outcomes are not comparable, it indicates that the model is not stable enough to use for estimating future land-use change. In that case, it might be necessary to split the model into sub-components to find the cause of the instability and thus validate its sub-components first.

\subsection{Scale Issues in Land-Use Modelling}

Scale and land-use modelling are interwoven phenomena. Choice of scale of modelling is of influence on the result as was described by Benenson (2007), who discussed the theoretical impact of scale on CA transition rules. Wu and Li (2006) 


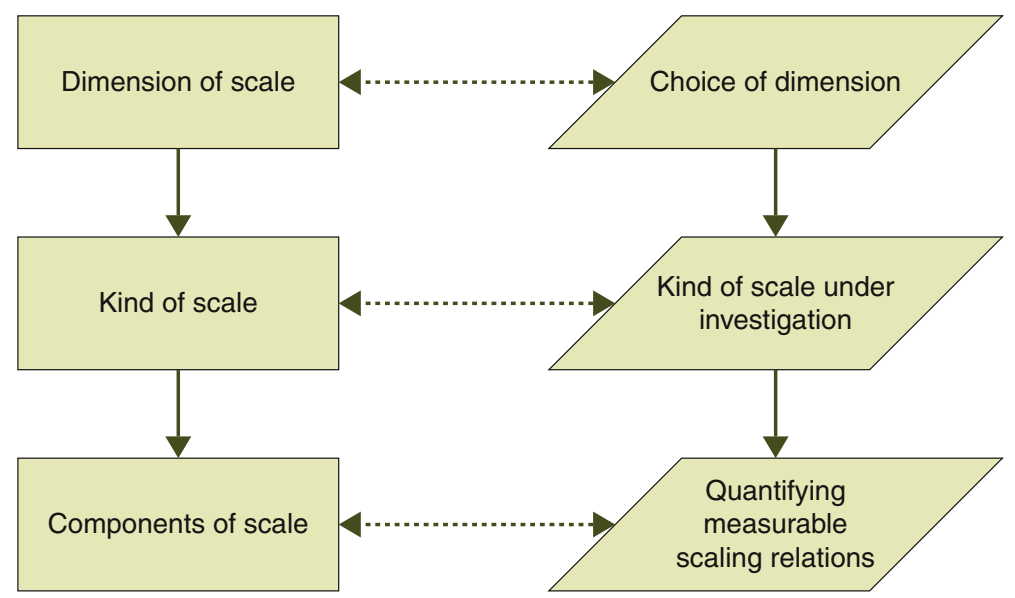

Fig. 3.5 Hierarchy of scale (after Wu \& Li, 2006)

distinguish a conceptual hierarchy of scale (see Fig. 3.5) consisting of three levels: dimension, kind, and components of scale. Each of these levels is briefly described below.

The first level is the dimension of scale, which can be temporal, spatial or institutional (Bürgi, Hersperger \& Schneeberger, 2005; Dungan et al., 2002; Wu \& $\mathrm{Li}, 2006$ ). Temporal scale is measured in time steps (e.g. years), spatial scale is measured in resolution (e.g. kilometres) and institutional scale is measured in institutions (e.g. two countries). Institutional scale is a special kind of scale since two institutions are never of the same size. Furthermore the institutional scale is discrete, whereas time and space are continuous.

On the second level of scale, Wu and Li (2006) distinguish different kinds of scale; see the left-hand side of Fig. 3.6. The intrinsic scale is the scale on which a process operates in reality. The process is observed by humans on an observation scale. When a certain process is modelled the modeller has to choose a modelling scale, which can be, but is not necessarily, the same as the observation scale. The modelling results are then presented to the policy-makers, who will look on a policy scale at the process. For explanatory purposes, the kinds of scale are related to land cover and land-use change in Fig. 3.6. This figure distinguishes between the land cover that can be observed (e.g. building) and the use to which the land is put (e.g. residential or commercial). Analysis of spatial developments normally starts with observation of land cover change processes using remote sensing (with a resolution that can range from $1 \mathrm{~m}$ up to $30 \mathrm{~m}$ ). The analysis or modelling scale is normally an aggregate of the observation scale. In case of the Dutch CBS data used in the Land Use Scanner this is a resolution of $25 \mathrm{~m} \times 25 \mathrm{~m}$. The policy scale depends strongly on the focus of the policy theme and may involve a variety of scales. Our focus in this chapter is the process of land-use change, which is often more complex than the process of land-cover change because of the human factor. Different core principles (e.g. neighbourhood interaction) exist to describe the way land-use change processes 


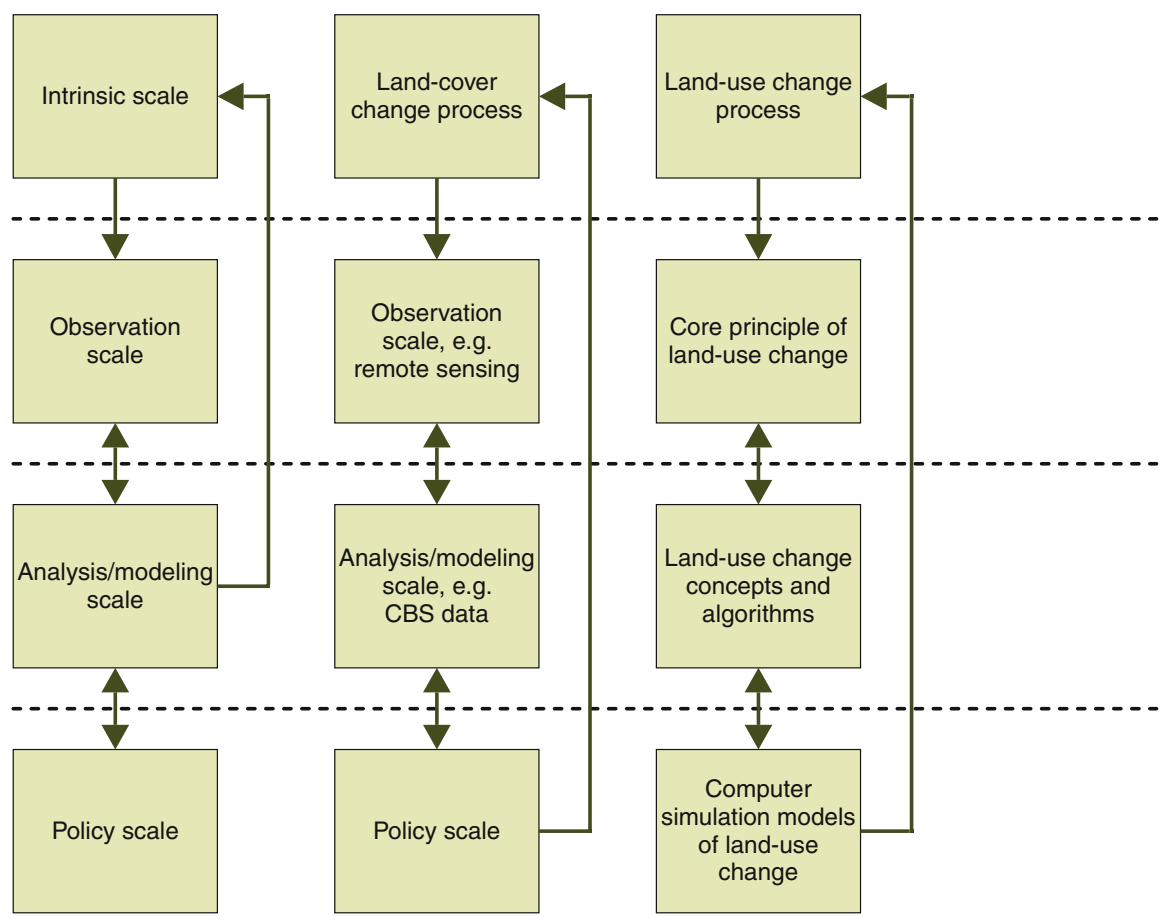

Fig. 3.6 Kinds of scale in modelling land-use change (after Wu \& Li, 2006)

are supposed to have taken place. These can be seen as the observation scale of land-use change. Land-use change concepts and the algorithms that express them can then be thought of as the modelling scale of the land-use change process. The policy scale can be found in the outcomes of the models. Since policies influence processes of land-use change, there are feedback links back to the intrinsic scale, i.e. the land-use change process.

The third and last hierarchical level of scale relates to its components and is about quantifying and developing measurable scaling relations. These include cartographic scale, grain, extent, coverage and spacing (Wu \& Li, 2006).

Figure 3.6 also places the framework in Fig. 3.1 in perspective. The implications of scale issues are important in the case of land-use modelling (Parker et al., 2001). Scaling difference between the policy scale and the intrinsic scale should be as small as possible to avoid model-induced errors. If, for example, the modelling scale level chosen is too large, the actual process of land-use change may be overlooked.

In recent research, the focus (as far as scale issues are concerned) has been on spatial correlation of land use and land-use change (Overmars, de Koning \& Veldkamp, 2003; Verburg et al., 1999). Analysis at different temporal scales is more difficult due to incomplete or inconsistent time series of the required spatial data, (e.g. Li \& Yeh, 2001). The institutional level of scale differs per country and case study. 


\subsection{Conclusions and Discussion}

The literature analysis we present in this chapter is a first step towards acquiring a better understanding of the usability of land-use models. Knowing the core principles of a model can help a modeller use it in the right way and help the policymaker to understand the basis of the model. It makes the 'black box' - which models sometimes are to policy-makers (and even modellers) - less black. To illustrate the degree of complexity of advanced models, it is estimated that someone who is new to such a model needs at least 2-3 months before he or she is fully capable of understanding and working with the model.

Of the many models that exist, this report mentions only a few. Some models are clearly too complex, which makes them difficult to implement at other spatial locations, such as UrbanSim of which the implementation at the Environmental Assessment Agency illustrated the difficulty to use this model in the context of a different location and data availability.

Care should be taken not to judge models by their spatial performance alone. Over-fitting of models is a well-known trap. There is a balance to be found in calibrating a model for a certain spatial location and the usability of this calibration for other spatial locations. Research aims might also influence this. Perhaps the aim is to build a model that can be used immediately at different spatial locations, or perhaps it is to build a model that has to be calibrated for each spatial location. The first option, a model that can be used at different spatial locations, seems the most preferred one.

It is better to use simpler models because it is easy to explain what happens and the results are easier to explain. It seems that the complexity land-use modellers are trying to capture is not something that can be modelled. There are simply too many factors to be taken into account. Agent-based models focus strongly on process resemblance, artificial neural networks focus strongly on spatial resemblance. Changing the focus of the model will result in a loss of its strong points, so a trade-off has to be made in which certain models are used to optimal effect.

More care should also be taken in listening to policy-makers. What do they actually need? This is currently the focus of the work of several PhD students in the Netherlands.

It is our opinion that - at least for the Netherlands - using a model such as Land Use Scanner, which works with suitability, demand and supply, is a good approach, but not for creating beautiful maps. Rather, it should be used more with a technique such as variant-invariant region, as Brown, Page, Riolo, Zellner, and Rand (2005) show in their paper on path dependence in agent-based models of land use. This works as follows. Different scenario's can be analyzed in the computer simulation model. Maybe from the results it can be seen that certain developments will always take place (invariant regions) or that certain areas are high in demand and their future use depends on the chosen scenario (variant regions). Then bottlenecks for spatial planning are recognised and policy-makers can make their decision instead of the model making the decision for them. 


\subsection{Themes for Future Research}

Inspired by the literature review, we have selected several themes that warrant future research:

- thematic classification (number of land-use classes);

- extent (size of the study area);

- resolution (cell size); and

- time step (discrete interval in time).

The relation between these themes is shown in Fig. 3.7. Extent and cell size are assumed to be strongly correlated; for a study area with a specific extent, a certain resolution will be optimal. If a study area, for example, only measures $4 \mathrm{~km} \times$ $4 \mathrm{~km}$, it does not make sense to use a cell size of $1 \mathrm{~km} \times 1 \mathrm{~km}$. Sizes of $100 \mathrm{~m} \times$ $100 \mathrm{~m}$ or $25 \mathrm{~m} \times 25 \mathrm{~m}$ would then be more appropriate to discern spatial patterns within the area. The thematic classification of land use is often related to the extent and resolution of the case study. With increasing diversity (increasing number of classes), the minimal extent for a specific cell size increases.

Time step is related to all three (extent of study area, cell size and thematic classification), but the chosen time step mostly depends on the choice of classification and the development or amount of land-use change in a study area. If there is little change over time, the ideal time step for modelling can be larger than when there is a lot of change. Intuitively, if there are small time steps there is room to simulate more diversity (more different classes) than if there are large time steps. Of course, data is scarce, so research is often limited to a time step dictated by data supply.

For each of the four themes described above we list a few research options. These options focus on the Netherlands as they are meant to help the further development of the Dutch LUMOS models.

\section{Thematic Classification}

The definition of a thematic classification is a basic step in developing a land-use simulation model. Does a model simulate two (e.g. built or non-built) or more land uses? And what is the maximum number of land-use classes that can be simulated given a certain cell size and extent of a study area? In other words, what would be a

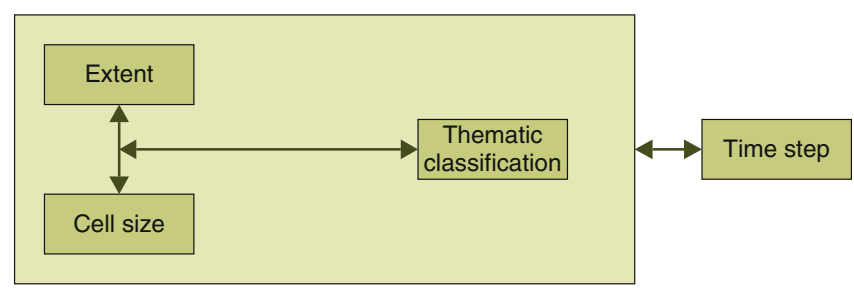

Fig. 3.7 Relation between cell size, extent of study area, thematic classification and time step 
sound choice of the number of classifications to be used in land-use modelling given a certain area and cell size?

To start finding an answer the following option can be considered. First assume a certain extent of study area and cell size. Then the number of land-use classes is varied (from 2 up to 10). This can be investigated for different spatial locations. Although it may also be possible to approach this problem theoretically, i.e. with complicated mathematical equations, the ultimate goal is only to provide a rule of thumb with which modellers can determine an optimum number of classes.

\section{Extent of Study Area}

Often the choice of extent of a study area is arbitrary and data dependent. The bigger the study area (assuming cell size remains the same), the more land-use cells have to be allocated. Intuitively, there is a minimum extent that a study area should have before the use of a land-use model starts to make sense. A Markov model can be used to start off with a study area extent of four cells and only two classes (most extreme) and then, by making the extent bigger for each time step, an optimal extent can be found after which, statistically, the Markov model performs worse than not modelling (persistence).

\section{Resolution (Cell Size)}

For the Netherlands, further research could be done on the effect of using varying cell sizes $(25 / 100 / 250 / 500 / 1,000 \mathrm{~m})$ for different spatial locations in the country. The Land Use Scanner model offers the opportunity to simulate at all these resolutions, but the impact of these different choices has not yet been analysed systematically.

\section{Time Step}

To better understand ongoing spatial developments an analysis of historic developments is extremely useful. For the Netherlands several data sets are available for the years 1960-2000, with 10-year time steps. From these land-use maps, Markov matrices can be constructed. It can be investigated whether the stationarity principle holds or that the rate of change for certain classes changes over time. The matrix can be used to extrapolate land use into the future, validate the current model and obtain information on the impact of spatial planning regulations in the observed period.

\section{References}

Agarwal, C., Green, G. M., Grove, J. M., Evans, T. P., \& Schweik., C. M. (2001). A review and assessment of land-use change models: Dynamics of space, time, and human choice. Bloomington, IN: South-Burlington, Center for the Study of Institutions Population, and Environmental Change, Indiana University.

Alcamo, J., Kreileman, G. J. J., Krol, M. S., \& Zuidema, G. (1994a). Modeling the global societybiosphere-climate system: Part 1: Model description and testing. Water, Air, \& Soil Pollution, 76(1-2), 1-35. 
Alcamo, J. G. J., van den Born, A. F., Bouwman, B. J., de Haan, K., Klein Goldewijk, O., Klepper, J., et al. (1994b). Modeling the global society-biosphere-climate system: Part 2: Computed scenarios. Water, Air, \& Soil Pollution, 76(1-2), 37-78.

Alonso, W. F. (1964). Location and land use. New Haven, CT: Harvard University Press.

Arentze, T. A., \& Timmermans, H. J. P. (2000). Albatross, a learning based transportation oriented simulation system. Eindhoven: Eindhoven University.

Baker, W. L. (1989). A review of models of landscape change. Landscape Ecology, 2(2), 111-133.

Balmann, A. (1996). Farm-based modelling of regional structural change: A cellular automata approach. European Review of Agricultural Economics, 24, 85-108.

Batty, M., \& Xie, Y. (1994). From cells to cities. Environment \& Planning B: Planning \& Design, 21, S31.

Bella, I. E. (1971). A new competition model for individual trees. Forest Science, 17(3), 364-372.

Benenson, I. (2007). Warning! The scale of land-use CA is changing! Computers, Environment and Urban Systems, 31(2), 107-113.

Borsboom-van Beurden, J. A. M., Boersma, W. T., Bouwman, A. A., Crommentuijn, L. E. M., Dekkers, J. E. C., \& Koomen., E. (2005). Spatial impressions - Visualisation of future land use in the Netherlands. Bilthoven - The Netherlands, Netherlands Environmental Assesment Agency-550016003/2005.

Briassoulis, H. (2000). Analysis of Land use change: Theoretical and modeling approaches. Morgantown, WV: West Virginia University.

Brown, D. G., Page, S., Riolo, R., Zellner, M., \& Rand, W. (2005). Path dependence and the validation of agent-based spatial models of land use. International Journal of Geographical Information Science, 19(2), 153-174.

Bürgi, M., Hersperger, A. M., \& Schneeberger, N. (2005). Driving forces of landscape change Current and new directions. Landscape Ecology, 19(8), 857-868.

Burnham, B. O. (1973). Markov intertemporal land use simulation model. Southern Journal of Agricultural Economics, 5(1), 253-258.

Chomitz, K. M., \& Gray, D. A. (1996). Roads, land use, and deforestation: A spatial model applied to Belize. World Bank Economic Review, 10(3), 487-512.

Couclelis, H. (1985). Cellular worlds: A framework for modeling micro - macro dynamics. Environment and Planning A, 17(5), 585-596.

deMaris, A. (1992). Logit modeling: Practical applications, University of Iowa-07-086.

de Nijs, T. C. M., de Niet, R., \& Crommentuijn, L. (2004). Constructing land-use maps of the Netherlands in 2030. Journal of Environmental Management, 72(1-2), 35-42.

Dungan, J. L., Perry, J. N., Dale, M. R. T., Legendre, P., Citron-Pousty, S., Fortin, M. J., et al. (2002). A balanced view of scale in spatial statistical analysis. Ecography, 25(5), 626-640.

Engelen, G., White, R., Uljee, I., \& Drazan, P. (1995). Using cellular automata for integrated modelling of socio-environmental systems. Environmental Monitoring and Assessment, 34(2), 203-214.

Fearnside, P. M. (1996). Amazonian deforestation and global warming: Carbon stocks in vegetation replacing Brazil's Amazon forest. Forest Ecology and Management, 80(1-3), 21-34.

Ferrand, N. (1996). Modelling and supporting multi-actor planning using multi-agents systems. Santa Barbara, CA: Third NCGIA Conference on GIS and Environmental Modelling.

Fujita, M., Krugman, P., \& Venables, A. J. (1999). The spatial economy. London: The MIT press.

Gardner, M. (1970). Mathematical Games: The fantastic combinations of John Conway's new solitaire game 'life'. Scientific American, 223, 120-123.

Geertman, S., Hagoort, M., \& Ottens, H. (2007). Spatial-temporal specific neighbourhood rules for cellular automata land-use modelling. International Journal of Geographical Information Science, 21(5), 547-568.

Grimm, V., Berger, U., Bastiansen, F., Eliassen, S., Ginot, V., Giske, J., et al. (2006). A standard protocol for describing individual-based and agent-based models. Ecological Modelling, 198(1-2), 115-126. 
Hagoort, M. (2006). The Neighbourhood Rules. Land-use interaction, urban dynamics and cellular automata modeling (300p). PhD, Faculty of geosciences, Utrecht University, Utrecht.

Heistermann, M., Muller, C., \& Ronneberger, K. (2006). Land in sight?: Achievements, deficits and potentials of continental to global scale land-use modeling. Agriculture, Ecosystems \& Environment, 114(2-4), 141-158.

Hilferink, M., \& Rietveld, P. (1999). LAND USE SCANNER: An integrated GIS based model for long term projections of land use in urban and rural areas. Journal of Geographical Systems, $1(2), 155-177$.

Hunt, J. D., Kriger, D. S., \& Miller, E. J. (2004). Current operational urban land-use-transport modelling frameworks: A REVIEW. Transport Reviews, 25(3), 329-376.

Koomen, E., Loonen, W., \& Hilferink, M. (2008). Climate-change adaptations in land-use planning; A scenario-based approach. In L. Bernard, A. Friis-Christensen, \& H. Pundt (Eds.), The European information society; Taking geoinformation science one step further (pp. 261-282). Berlin: Springer.

Koomen, E., \& Stillwell, J. (2007). Modelling land-use change; Theories and methods. Chapter 1. In E. Koomen, J. Stillwell, A. Bakema, \& H. J. Scholten (Eds.), Modelling land-use change; Progress and applications (pp. 1-21). Dordrecht: Springer.

Koomen, E., J. Stillwell, A. Bakema, \& H. J. Scholten, (Eds.). (2007). Modelling land-use change. Progress and applications. Dordrecht, The Netherlands: Springer.

Krugman, P. (1991). Geography and trade (Gaston Eyskens lecture series). Leuven: Leuven University Press.

Krugman, P. (1999). The Role of Geography in Development. International Regional Science Review, 22(2), 142-161.

Kuijpers-Linde, M., Geurs, K. T., Knoop, J. M., Kuiper, R., Lagas, P., Ligtvoet, W., et al. (2007). Nederland Later, Tweede Duurzaamheidsverkenning, deel fysieke leefomgeving Nederland. Bilthoven.

Lambin, E. F., Rounsevell, M. D. A., \& Geist, H. J. (2000). Are agricultural land-use models able to predict changes in land-use intensity? Agriculture, Ecosystems \& Environment, 82(1-3), 321-331.

Lambin, E. F., Turner, B. L., Geist, H. J., Agbola, S. B., Angelsen, A., Bruce, J. W., et al. (2001). The causes of land-use and land-cover change: Moving beyond the myths. Global Environmental Change, 11(4), 261-269.

Langdon, W. B. (1998). Genetic programming and data structures (350p). MSc, University College, London .

Le Page, C., Bousquet, F., Bakam, I., Bah, A., \& Baron, C. (2000). CORMAS: A multiagent simulation toolkit to model natural and social dynamics at multiple scales. Wageningen: Workshop 'The ecology of scales'.

Lesschen, J. P., Verburg, P. H., \& Staal, S. J. (2005). Statistical methods for analysing the spatial dimension of changes in land use and farming systems, International Livestock Research Institute LUCC Focus 3 Office.

Li, X., \& Yeh, A. G.-O. (2001). Calibration of cellular automata by using neural networks for the simulation of complex urban systems. Environment and Planning A, 33(8), 1445-1462.

Liao, T. F. (1994). Interpreting probability models. Logit, Probit, and Other Generalized Linear Models, University of Iowa-07-101.

Ligtenberg, A., Bregt, A. K., \& Lammeren, Rv. (2001). Multi-actor-based land use modelling: Spatial planning using agents. Elsevier, 56, 21-33.

Lopez, E., Bocco, G., Mendoza, M., \& Duhau, E. (2001). Predicting land-cover and land-use change in the urban fringe: A case in Morelia city, Mexico. Landscape and Urban Planning, $55,271-285$.

LUMOS (2005). Platform for land use modeling in the Netherlands. Lumospro. (2007). Project team website. www.lumospro.nl

Mas, J. F., Puig, H., Palacio, J. L., \& Sosa-Lopez, A. (2004). Modelling deforestation using GIS and artificial neural networks. Environmental Modelling \& Software, 19(5), 461-471. 
Matthews, R., Gilbert, N., Roach, A., Polhill, G., \& Gotts, N. (2007). Agent-based land-use models: A review of applications. Landscape Ecology, 22, 1447-1459.

McGarigal, K., \& Marks., B. J. (1995). FRAGSTATS: Spatial pattern analysis program for quantifying landscape structure. Portland, OR: US, Department of Agriculture, Forest Service, Pacific Northwest Research Station-PNW-GTR-351.

Meyer, W. B., \& Turner, B. L. (1992). Human population growth and global land-use/cover change. Annual Review of Ecology and Systematics, 23(1), 39-61.

Moeckel, R., Schurmann, C., \& Wegener, M. (2002). Microsimulation of land use. 42nd European Congress of The Regional Science Association. Dortmund: Institut fur Raumplanung, University of Dortmund.

Muller, M. R., \& Middleton, J. (1994). A Markov model of land-use change dynamics in the Niagara Region, Ontario, Canada. Landscape Ecology, 9(2), 151-157.

Nelson, G. C., \& Hellerstein, D. (1997). Do roads cause deforestation? Using satellite images in econometric analysis of land use. American Journal of Agricultural Economics, 79(1), 80-88.

Overmars, K. P., de Koning, G. H. J., \& Veldkamp, A. (2003). Spatial autocorrelation in multi-scale land use models. Ecological Modelling, 164(2-3), 257-270.

Overmars, K. P., de Groot, T., \& Huigen, M. G. A. (2007). Comparing inductive and deductive modeling of land use decisions: Principles, a model and an illustration from the Philippines. Human Ecology, 35, 439-452.

Parker, D. C., Berger, T., \& Manson, S. M. (2001). Agent-based models of land-use and land-cover change. Adaptive agents, intelligence and emergent human organization: Capturing complexity through agent-based modelling. Irvine, CA: LUCC International Project Office.

Pijanowski, B. C., Brown, D. G., Shellito, B. A., \& Manik, G. A. (2002). Using neural networks and GIS to forecast land use changes: A land transformation model. Computers, Environment and Urban Systems, 26(6), 553-575.

Pijanowski, B. C., Pithadia, S., Shellito, B. A., \& Alexandridis, K. (2005). Calibrating a neural network-based urban change model for two metropolitan areas of the Upper Midwest of the United States. International Journal of Geographical Information Science, 19(2), 197-215.

Pinto, N. N., \& Antunes, A. P. (2007). Cellular automata and urban studies: A literature survey. Architecture, City and Environment, 4, 471-486.

Pontius, R. G., Boersma, W., Castella, J.-C., Clarke, K., De Nijs, T., Dietzel, C., et al. (2008). Comparing the input, output, and validation maps for several models of land change. Annals of Regional Science, 42(1), 11-37.

Pontius, R. G., Cornell, J. D., \& Hall, C. A. S. (2001). Modeling the spatial pattern of land-use change with GEOMOD2: Application and validation for Costa Rica. Agriculture, Ecosystems \& Environment, 85(1-3), 191-203.

Ricardo, D. (1817). On the Principles of Political Economy and Taxation, Library of Economics and Liberty.

Scopus. (2008). The largest abstract and citation database of research literature and quality web sources.

Silva, E. A., \& Clarke, K. C. (2002). Calibration of the SLEUTH urban growth model for Lisbon and Porto, Portugal. Computers, Environment and Urban Systems, 26(6), 525-552.

Sinclair, R. (1967). Von Thunen and Urban Sprawl. Annals of the Association of American Geographers, 57(1), 72-87.

Skapura, D. (1996). Building neural networks. New York: ACM Press.

Tobler, W. (1979). Cellular geography. In S. Gale \& G. Olsson (Eds.), Philosophy in geography (pp. 379-386). Dordrecht: Reidel.

Turner, B. L., Skole, D., Sanderson, S., Fischer, G., Fresco, L., \& Leemans., R. (1995). Land-Use and Land-Cover Change Science/Research Plan, International Human Dimensions Programme on Global Environmental Change-7.

Veldkamp, A., \& Fresco, L. O. (1996). CLUE: A conceptual model to study the conversion of land use and its effects. Ecological Modelling, 85(2-3), 253-270. 
Verburg, P. H., de Koning, G. H. J., Kok, K., Veldkamp, A., \& Bouma, J. (1999). A spatial explicit allocation procedure for modelling the pattern of land use change based upon actual land use. Ecological Modelling, 116(1), 45-61.

Verburg, P. H., van Eck, J. R. R., de Nijs, T. C. M., Dijst, M. J., \& Schot, P. (2004). Determinants of land-use change patterns in the Netherlands. Environment and Planning B: Planning and Design, 31(1), 125-150.

Verburg, P. H., Schot, P. P., Dijst, M. J., \& Veldkamp, A. (2004). Land use change modelling: Current practice and research priorities. GeoJournal, 61, 309-324.

von Thünen, J. H. (1966). Isolated state: An English edition of Der isolierte Staat. New York: Pergamom Press.

Waddell, P. (2002). UrbanSim: Modeling urban development for land use, transportation and environmental planning.

Wagner, P., \& Wegener, M. (2007). Urban land use, transport and environment models. disP, 3, $45-57$.

Walker, R. (2004). Theorizing land-cover and land-use change: The case of tropical deforestation. International Regional Science Review, 27(3), 247-270.

Walsh, S. E., Soranno, P. A., \& Rutledge, D. T. (2003). Lakes, Wetlands, and Streams as Predictors of land use/cover distribution. Environmental Management, 31(2), 198-214.

Wear, D. N., \& Bolstad, P. (1998). Land-use changes in southern appalachian landscapes: Spatial analysis and forecast evaluation. Ecosystems, 1(6), 575-594.

White, R., \& Engelen, G. (1994). Cellular dynamics and GIS: Modelling spatial complexity. Geographical Systems, 1, 237-253.

White, R., \& Engelen, G. (2000). High-resolution integrated modelling of the spatial dynamics of urban and regional systems. Computers, Environment and Urban Systems, 24(5), 383-400.

Wrigley, N. (1976). Introduction to the use of logit models in geography. Norwich: University of East Anglia-10.

Wu, J., \& Li, H. (2006). Concepts of scale and scaling. In J. Wu, K. B. Jones, H. Li, \& O. L. Loucks (Eds.), Scaling and uncertainty analysis in ecology: Methods and applications. New York: Springer, p. 6. 